\title{
Innovative Air-Transport Policy Formulation \& Analysis Conducive to Economic Growth and Sustainability
}

\author{
Reza G. Hamzaee, Ph.D.* \\ BOG-Distinguished Professor of Economics \\ Department of Economics, Political Science, and Sociology \\ Missouri Western State University
}

\begin{abstract}
The intuitive concept of strong economic effects of aviation and air transport has been unexceptionally supported by the abundantly clear evidence. Hence, formulation of a dynamic and sustainable policy, based on massive evidence, is considered as mandatory. Innovative policies would internalize major components of the existing positive externalities to enhance the success, efficiency, and viability of the industry, which would be conducive to economic development. This study applies an inductive method: Some evidence and empirically measured economic effects would lead to the formulation of an integrative economic policy framework that can be applied accordingly in the future.
\end{abstract}




\section{Introduction}

The economic impact of transportation, in general, and air transportation, in specific, has been clear and addressed appropriately at all times. Hence, the opportunity costs of any less than optimal and most efficient economic policy that would incorporate all the infrastructural growth potential into actual fruition would be too large. While in both of the following two tables, the economic contributions of civil aviation are demonstrated, in TABLE 2, billions of dollars of aviation-related manufacturing income are reported both for 2012.

TABLE 1: 2012 Economic Impact of Civil Aviation (Percent of Top Ten States' GDP)

\begin{tabular}{cc}
\hline State & Contribution to GDP \\
\hline Hawaii & $17.9 \%$ \\
Nevada & $12.1 \%$ \\
Arizona & $7.9 \%$ \\
Alaska & $7.5 \%$ \\
Florida & $7.2 \%$ \\
Washington & $6.7 \%$ \\
Colorado & $6.2 \%$ \\
Georgia & $5.7 \%$ \\
Utah & $5.6 \%$ \\
California & $4.7 \%$ \\
\hline Source: U.S. Department of Transportation \\
Federal Aviation Administration, January 2015, p. 6 \\
\multicolumn{2}{c}{ (Reorganized by the author) }
\end{tabular}

TABLE 2: Total Economic Output (Manufacturing): Aircraft, Aircraft Engine, and Parts Manufacturing Top Five States

(Top Five States, Billions of Dollars)

\begin{tabular}{lc}
\hline State & Manufacturing \\
\hline California & 34.9 \\
Washington & 25.4 \\
Texas & 16.3 \\
Connecticut & 13.4 \\
Arizona & 11.8 \\
\hline \multicolumn{2}{c}{ Source: U.S. Department of Transportation } \\
Federal Aviation Administration, January 2015, p. 8 \\
\multicolumn{2}{c}{ (Reorganized by the author) }
\end{tabular}

It is also evident from TABLE 3 that in many other economic-benefit criteria, such as aviation's relative productivity, income, passengers carried, tourist travelers, etc., aviation and air transport industry have a significant and sustainable positive impact. 
TABLE 3: Globalization \& Aviation Benefits - 2014

\begin{tabular}{|c|c|}
\hline Jobs Created & 62.7 million \\
\hline $\begin{array}{c}\text { Relative Productivity: } \\
\text { Aviation Jobs }\end{array}$ & 3.8 times more productive than other jobs \\
\hline Income & $\$ 2.7$ trillion \\
\hline If aviation were a country & $21^{\text {st }}$ biggest in GDP Size \\
\hline Passengers Carried & 3.3 billion (2014) \\
& 3.57 billion (2015) \\
\hline Tourist Travelers & $54 \%$ of all international tourists traveled by air \\
\hline No of Commercial Airlines & 1402 \\
\hline Commercial Aircraft in \\
Service & 26,065 \\
\hline Airports with Scheduled & 3,883 \\
\hline Commercial Flights & 32.8 million (2014) \\
\hline World-Wide Commercial & 34.8 million (2015) \\
Flights
\end{tabular}

Source: Aviation Benefits beyond Borders - Global Summary, ATAG, June 2016

(Reorganized \& tabulated by the author)

The 20-year forecast of international air traffic growth seems to be promising, as is clear from TABLE 4.

TABLE 4: International Air Traffic Growth Forecast: 2014-2034

\begin{tabular}{|c|c|c|c|}
\hline Africa & $5.4 \%$ & APEC & $3.9 \%$ \\
\hline Asia-Pacific & $5.1 \%$ & European Union & $3.6 \%$ \\
\hline Europe & $3.6 \%$ & Small Island States & $4.9 \%$ \\
\hline Latin America \& Caribbean & $4.7 \%$ & Developing Countries & $5.0 \%$ \\
\hline Middle East & $6.0 \%$ & OECD & $3.5 \%$ \\
\hline North America & $2.7 \%$ & World & $4.3 \%$ \\
\hline
\end{tabular}

Source: Aviation Benefits beyond Borders - Global Summary, ATAG, June 2016

(Reorganized \& tabulated by the author)

\section{Related Research Background}

The influence of transportation on different economies has never been ignored since ancient times. Civilization, as supported by socioeconomic, geopolitical and technological developments, has been leaning on transportation. As to air transport perspective, Button (2008) stresses appropriately:

From its earliest days, airlines were seen as having potential for providing high-speed mail services, and subsequently medium and long-term passenger transport. Technology now allows the carriage of much larger cargo pay-loads in a more reliable way. These strategic functions 
were used to pursue internal national policies of social, political, and economic integration within large countries such as Canada, the US, and Australia, but also took on international significance from the 1930s within the Imperial geopolitical systems centered mainly on the UK, France, Germany, and other European countries when technology allowed for intercontinental services to be developed. (p.7)

Button (2008) has also highlighted the airlines' attempts in covering their costs through many ways, including subsidies, service bundling, and even vertical integration. He refers to some example of historical experiences such as American Airlines initiating the computer reservation systems (CRS). He also uses the experiences of strong business ties and cooperation between Boeing and Pan American on the one hand and those of Lockheed and TWA in building and using aircraft.

Hamzaee \& Vasigh (2006) offered a theoretical framework, in which a mathematical model of airport-airlines cost-revenue sharing is recommended, which by itself would facilitate some internalization of external benefits in such a way that both independently operated entities would be incorporated into some sort of holding company.

Hamzaee \& Vasigh (2001 and 2002) in their two other separate studies on enhancement of airport efficiency, applied benchmarking (2001) and total factor productivity model (2002), using many airports and airlines data at the time. Obviously airports' efficient operations would facilitate trade and the desired sustainable economic growth. In the following section, some theoretical model are formulated and offered through applying the existing knowledge on aviation strengths and challenges. A series of aviation (industrial) policy conducive to more investment and infrastructure effects on the economy would be the center piece of the proposed models.

\section{The Framework and Methodology}

\section{A Proposed General Framework:}

$Y_{t}=f\left(X_{i t}, T r_{j t}, T e c_{h t}\right)$

$\mathrm{Y}_{\mathrm{t}}=$ National output, real GDP in period $\mathrm{t}$

$\mathrm{X}_{\mathrm{it}}=$ Real spending on ith resource in period $\mathrm{t}$, where $\mathrm{i}=1,2, \ldots, \mathrm{n}$

$\operatorname{Tr}_{\mathrm{jt}}=$ Real spending on $\mathrm{jth}$ transportation in period $\mathrm{t}$, where $\mathrm{j}=1,2, \ldots, \mathrm{m}$

$\mathrm{Tec}_{\mathrm{ht}}=$ Real spending on hth type of technology in period $\mathrm{t}$, where $\mathrm{h}=1,2, \ldots, \mathrm{k}$

To stress the share of air transportation relative to all forms of transportation, let's adopt ATA $_{t}$ defined in (2), as follows:

$$
A T A_{t}=\frac{A A T_{t}}{\sum_{j=1}^{m} T r_{j t}}
$$

$\mathrm{ATA}_{\mathrm{t}}=$ All Air Transport in period $\mathrm{t}$ as a fraction of the entirety of all the transportations made in period $t$, all measured in real spending. 
Assuming an aggregate Cobb-Douglas production function, equation (1) can be restated as:

$$
\begin{aligned}
& Y_{t}=\prod_{i=1}^{n} X_{i t}^{\alpha_{i}} \prod_{h=1}^{k} \operatorname{Tec}_{h t}{ }^{\beta_{h}} \operatorname{ATA}_{t}^{\delta} \\
& Y_{t}=\alpha_{0}+\sum_{i=1}^{n} \alpha_{i} \log _{i t}+\sum_{h=1}^{k} \beta_{h} \operatorname{LogTec}_{h t}+\delta \log A T A_{t}
\end{aligned}
$$

\section{An Infrastructure-Investment Enhancement Policy for Air-transport Industry:}

In order to enhance air-transport industry, some real incentives need to be built into the taxation formula. That approach would introduce an effective cost-benefit perspective into operational management in an attempt to optimize their services and activities. The author suggests the following investment model that should incorporate some policy-variables, including both punitive as well as persuasive measures.

ATK $=\mathbf{a}_{0}-\mathbf{a}_{1}$ TAR $-\mathbf{a}_{2}$ FL $+\mathbf{a}_{3}$ RORA $-\mathbf{a}_{4}$ RSK

ATK $=$ Air-transport capital expenditures

$\mathrm{TAR}=$ Tax rates on air-transport revenues

$\mathrm{FL}=$ Fuel used for air-transport purposes

RORA $=$ Rate of return on air-transport capital

RSK $=$ Expected risk index on air-transport investment

$\mathrm{a}_{\mathrm{i}}=$ all parameters for $\mathrm{i}=0,1, \ldots, 4$

The policy-focused tax rates on air-transport revenues are proposed to come into effect through the following formula:

$\mathbf{T A R}=\mathbf{t}_{0}-\mathbf{t}_{1} d E M A+t_{2}$ PDIS $-t_{3}$ APLA $-t_{4}$ FAAC

$\mathrm{dEMA}=$ Percentage change in a contribution index of air-transport related infrastructural activities

PDIS $=$ Passengers dissatisfaction index

APLA $=$ Airport-airline joint capital expenditures (more theoretical analysis on this in subheading 3 , as will follow)

$\mathrm{FAAC}=\mathrm{FAA}-$ Security Compliance Index, which would be possible to dynamically evolve for more effective enhancement of environmental safety and overall security

$\mathrm{t}_{\mathrm{i}}=$ all parameters, for $\mathrm{i}=0,1, \ldots, 4$

ATAR $=(1-T A R) . B T R$ 
Plugging (6) into (7), the following will be resulted:

ATAR $=\left(1-t_{0}+t_{1} d E M A ~-t_{2}\right.$ PDIS + $t_{3}$ APLA + $t_{4}$ FAAC $) . B T R$

Equation (8) can be summarized in a general functional form of:

ATAR = $\mathbf{f}\left(t_{0}\right.$, dEMA, PDIS, APLA, FAAC, BTR $)$

ATAR $=$ Air-transport after-tax revenues

$\mathrm{BTR}=$ Before-tax revenues of air-transport enterprises

After tax earnings of air-transport enterprises would be influenced by the general tax rates, percentage change in corresponding employment, passengers' satisfaction, the extent of airportairline joint capital expenditures, compliance with the FAA safety and environmental regulations, and their actual activities, as measured by their before-tax earnings.

\section{A Theoretical Model of Airline-Airport Integration: Review of a Previous Work}

Related to my proposed theoretical framework of subheading 1 and 2, as discussed above, the author is providing a thorough excerpt of what was previously published (Hamzaee and Vasigh, 2006), where an airline-airport integrated operation optimization model, in which all three stakeholders, the airlines, airports, and their customers (of both airside and landside services) are incorporated. What connects the other two segments of my model with this segment of our theoretical work is APLA = Airport-airline joint capital expenditures (as introduced in the last section).

Various solutions for group optimization are analyzed. Beginning with the two general groups of airside and landside outputs to be produced, there are $n$ different resources to be used by both airlines and airports. Therefore, the $\mathrm{n}$ resource constraints are defined as:

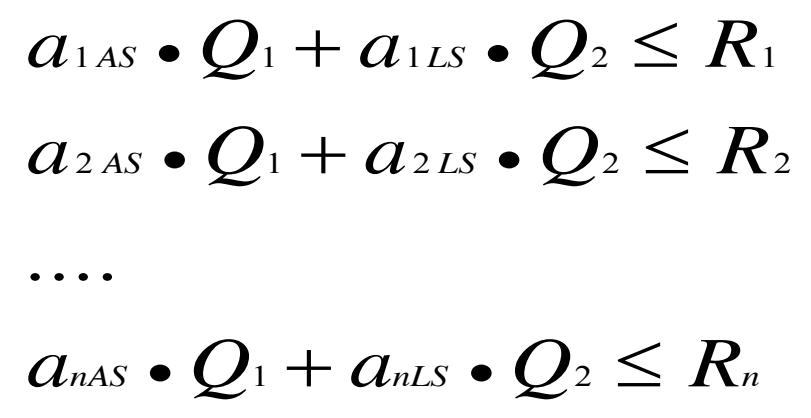

where,

$\mathrm{a}_{\mathrm{iAS}}=$ the amount of the ith resource necessary to produce one indexed unit of airside output (landing \& departure), for $\mathrm{i}=1,2, \ldots, \mathrm{n}$

$\mathrm{a}_{\mathrm{iLS}}=$ the amount of the ith resource necessary to produce one indexed unit of

landside services to customers at the airport, for $i=1,2, \ldots, n$

$\mathrm{Q}_{1}=$ the total indexed quantity of airside output (quantity of a composite output of landing/passengers + take off/passengers + miles/passengers, or alike)

$\mathrm{Q}_{2}=$ the total indexed quantity of landside output 
$R_{i}=\quad$ The total quantity of the ith utilized resource, for $i=1,2, \ldots, n$

In Figure 1, as an illustrating example, five of the aforementioned hypothetical resource constraints are graphed. Obviously, to arrive at a relevant production possibility frontier (the darker portions of the five constraints), all of the nth resource constraints listed above in (1), must be simultaneously implemented. This model is proposed to include only one airport (at a time) as integrated with all the airlines chartered to have movement (traffic) through it. An integration of all the resource constraints for one airport and all the airlines using that airport would be summarized in constraint (2), as follows next.

$$
\sum_{i=1}^{n}\left(a_{i F L} \cdot Q_{1}+a_{i L S} \cdot Q_{2}\right) \leq \sum_{i=1}^{n} R_{i}
$$

which is an integrative resource constraint of one airport - only - along with those of all the airlines using it. Such resources, as an example, could include - but not limited to - the following list:

$\mathrm{R}_{1}=\quad$ quantity of Gas

$\mathrm{R}_{2}=$ number of pilots

$\mathrm{R}_{3}=$ number of airside personnel

$\mathrm{R}_{4}=$ number of aircraft

$\mathrm{R}_{5}=$ number of runways

$\mathrm{R}_{6}=$ number of maintenance bases

$\mathrm{R}_{7}=$ number of maintenance technicians and engineers

$\mathrm{R}_{8}=$ number of tower controllers

$\mathrm{R}_{9}=$ amount of computer hardware and software to utilize

$\mathrm{R}_{8}=$ number of airlines' on-land employees excluding airside personnel, technicians and engineers

$\mathrm{R}_{7}=\quad$ number of landside operational employees

$\mathrm{R}_{10}=$ number of security personnel

$\mathrm{R}_{11}=$ number of janitorial employees

$\mathrm{R}_{12}=$ number of value of security facilities

$\mathrm{R}_{13}=$ number of airport restaurants

\section{The Airlines-Airport Budget Line}

Then under competitive conditions, the following condition should hold:

$$
P_{1}=\mathrm{ATC}_{1}
$$


$\left(Q_{1}\right)$

Indexed

quantity of airside outputs

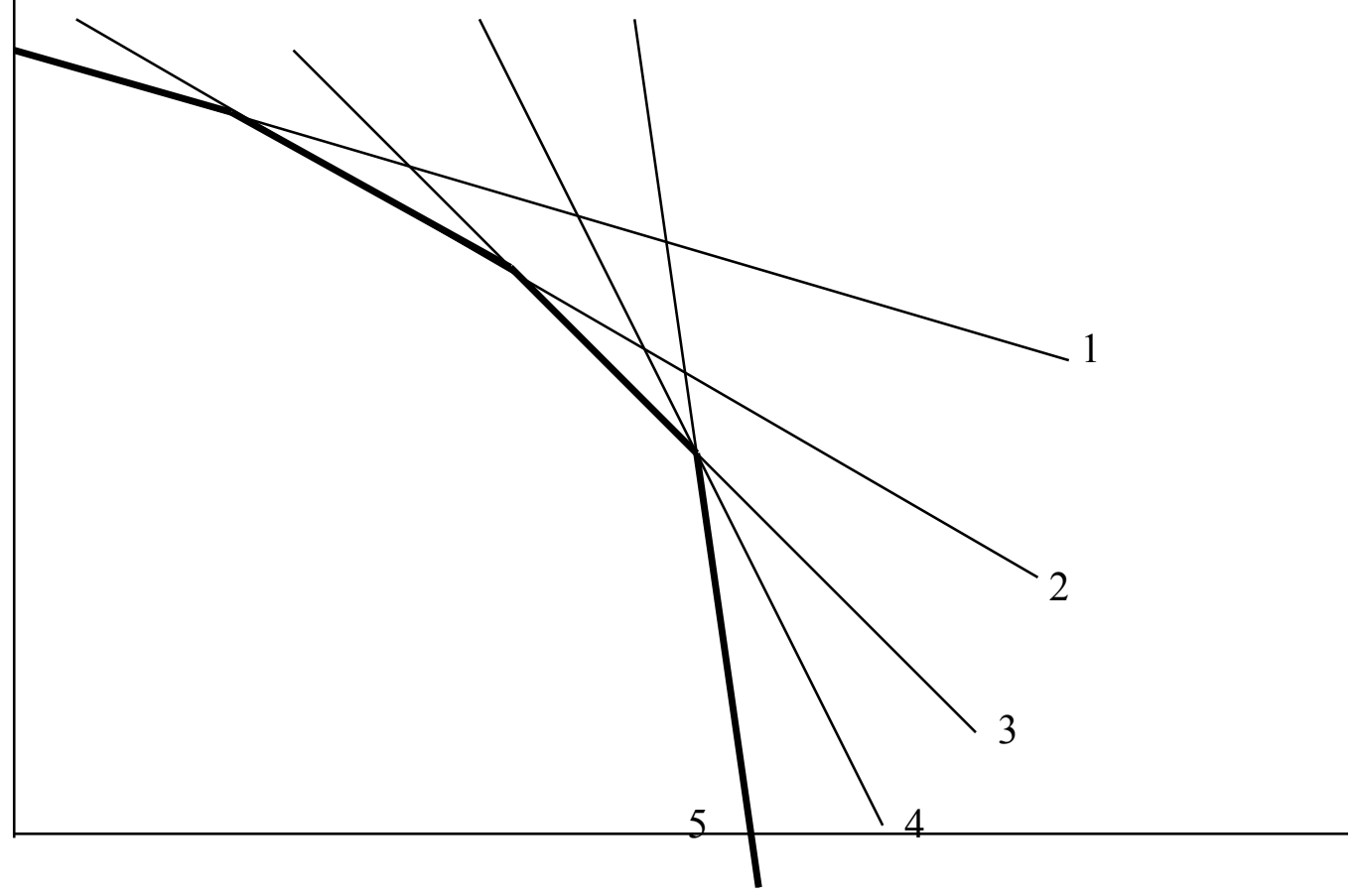

$\left(\mathrm{Q}_{2}\right)$

Indexed quantity of landside outputs

Figure 1.

An Integrated Airline-Airport Production Possibility Frontier

Also, by definition,

$$
A T C_{1}=\frac{\sum_{i=1}^{k} r_{i} R_{i}}{Q_{1}}
$$

which is the average resource cost, considering $\mathrm{k}$ different resources to be used for provision of airside output $\left(\mathrm{Q}_{1}\right)$.

$\mathrm{P}_{1}=\quad$ Indexed average price of a composite unit of output (landings/passengers, departures/passengers, plus miles/passengers of traveling)

$\mathrm{Q}_{1}=\quad$ Quantity of a composite output of landing/passengers $\left(\mathrm{q}_{1}\right)+$

takeoff/passengers $\left(\mathrm{q}_{2}\right)+$ Miles/passengers $\left(\mathrm{q}_{3}\right)$

$\mathrm{ATC}_{1}=$ 
average total cost of all resources needed for each composite unit of the airside output produced in a certain period of time

$r_{i}=\quad$ the rental price (cost) of the ith resource in production of airside output for $\mathrm{i}=1,2, \ldots, \mathrm{k}$

Comparing (3) and (4), the following definition, under competition, will result:

$$
P_{1}=\frac{\sum_{i=1}^{k} r_{i} R_{i}}{Q_{1}}
$$

Also, $\mathrm{P}_{2}$, the price of an indexed quantity of landside output $\left(\mathrm{Q}_{2}\right)$, can be similarly defined as:

$$
P_{2}=A T C_{2}=\frac{\sum_{j=1}^{m} r_{j} R_{j}}{Q_{2}}
$$

where:

$\mathrm{ATC}_{2}=$ average total cost of all land-side output supplied in a certain period of time

$r_{j}=$ the rental price (cost) of the jth resource in production of landside output for $\mathrm{j}=1,2, \ldots, \mathrm{m}$

$\mathrm{n}=$ $\mathrm{k}+\mathrm{m}$

Then the following relationship (7) will represent the budget constraint for the passengers and/or general customers, which would also represent the airlines-airport budget constraint, assuming that their incomes under competitive conditions would be the same as their total costs:

$$
\begin{aligned}
& \mathrm{P}_{1} \mathrm{Q}_{1}+\mathrm{P}_{2} \mathrm{Q}_{2} \leq \mathrm{B} \\
& \mathrm{B}=\mathrm{B}_{1}+\mathrm{B}_{2}
\end{aligned}
$$

$\mathrm{B}_{1}=$ Airlines total budget

$\mathrm{B}_{2}=$ Airport's total budget

$\mathrm{B}=\mathrm{B}_{1}+\mathrm{B}_{2}=$ Airportlines' total budget

Now, plugging (5) and (6) in (7), the following budget constraint will be resulted: 


$$
\begin{gathered}
\frac{\sum_{i=1}^{k} r_{i} R_{i}}{Q_{1}} \bullet Q_{1}+\frac{\sum_{j=1}^{m} r_{j} R_{j}}{Q_{2}} \bullet Q_{2} \leq B \\
Q_{1}=\left[\frac{B}{\frac{\sum_{i=1}^{k} r_{i} R_{i}}{Q_{1}}}\right]-\left[\frac{\left(\sum_{j=1}^{m} r_{j} R_{j}\right.}{\frac{Q_{2}}{Q_{i} R_{i}}}\right] Q_{2} \\
\text { (Q1-Intercept) } \\
\text { (Slope of the Budget Constraint) }
\end{gathered}
$$

$\mathbf{Q}_{1}=$ (Total airport-airlines integrated budget)

(Airlines average cost of operation)

$$
-\left[\frac{A T C_{\text {landside }}}{A T C_{\text {airside }}}\right] \cdot Q_{2}
$$

Now all the three stakeholders are put together into interaction, and find various possible optimization solutions to the model. In Figure 2, the optimum solution for all three groups is the same, $\mathrm{Q}_{1}^{*}$ and $\mathrm{Q}_{2}{ }_{2}$ should be produced and consumed. 


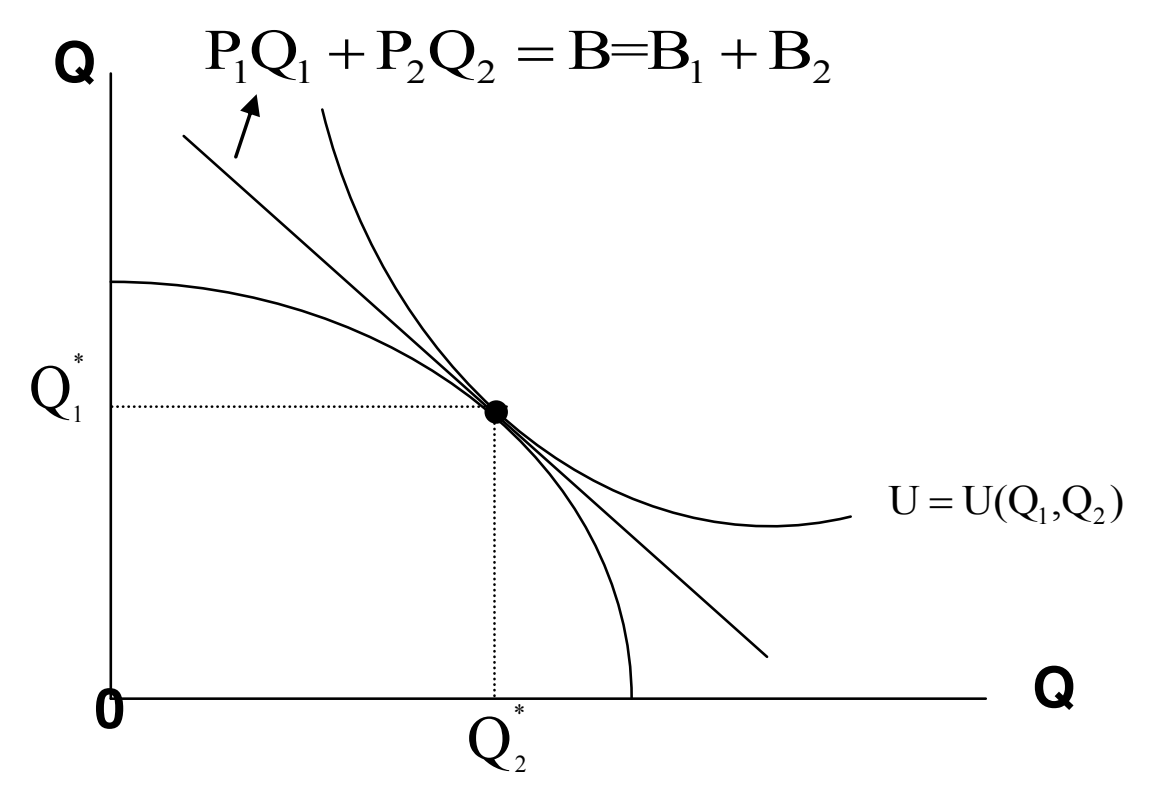

Figure 2

The optimum solution for all three groups is the same, $Q^{*}{ }_{1}$ and $Q^{*}{ }_{2}$ Should be produced and consumed

In Figure 3, consumers of both services would have a different optimal solution than the "airportlines" would. The consumers' preferences are more heavily towards airside than landside services. However, for the "airportlines" more of the landside and less of the airside would be the best solution.

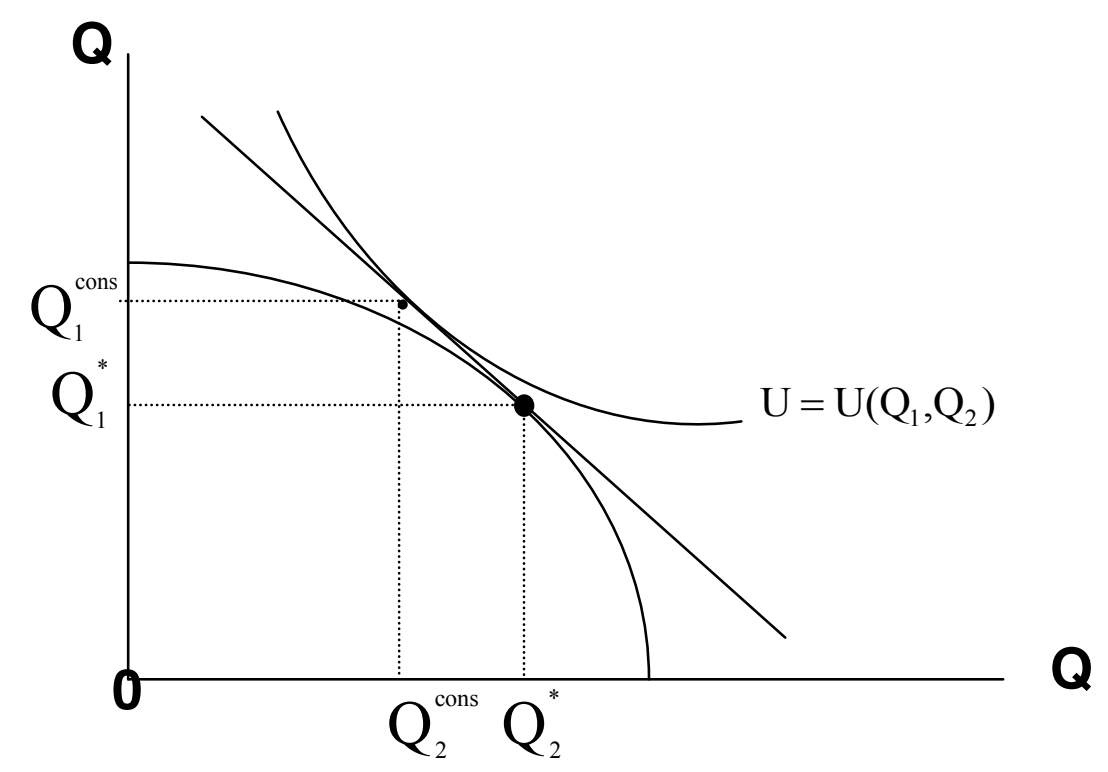

Figure 3

Consumers of both services would have a different optimal solution than would the "airportlines" 
In the following case (Figure 4), the providers (airports and airlines or just "airportlines") will have again a different optimal solution than the consumers would. Consumers are preferring more landside than airside services.

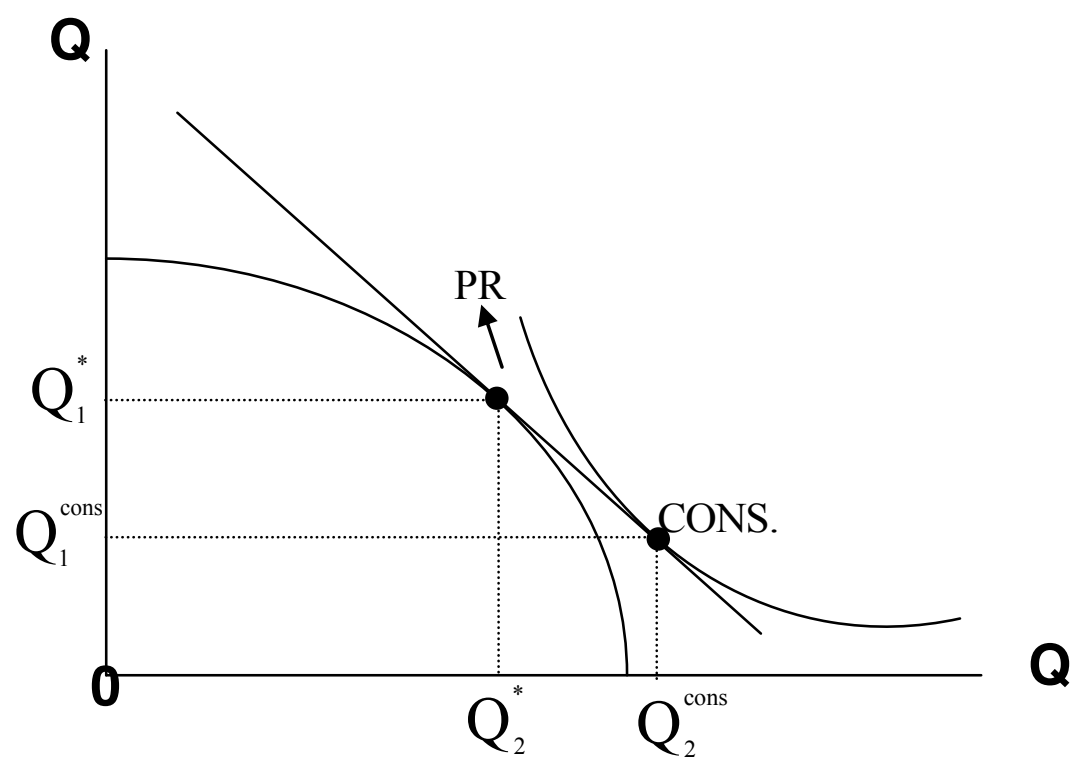

Figure 4

Consumers' biases are towards landside services

\section{A Trend Analysis of Some Aviation Data}

Focusing on several frequently watched airlines performance indicators, the author has applied some trend analysis. The linear trend estimations (Figures 6 and 7) have been revealed as optimal, considering various minimum error criteria.

Before focusing on some relevant trend estimations, Figure 5 indicates the significance of domestic and international air cargo revenues in terms of both frequencies and levels. 


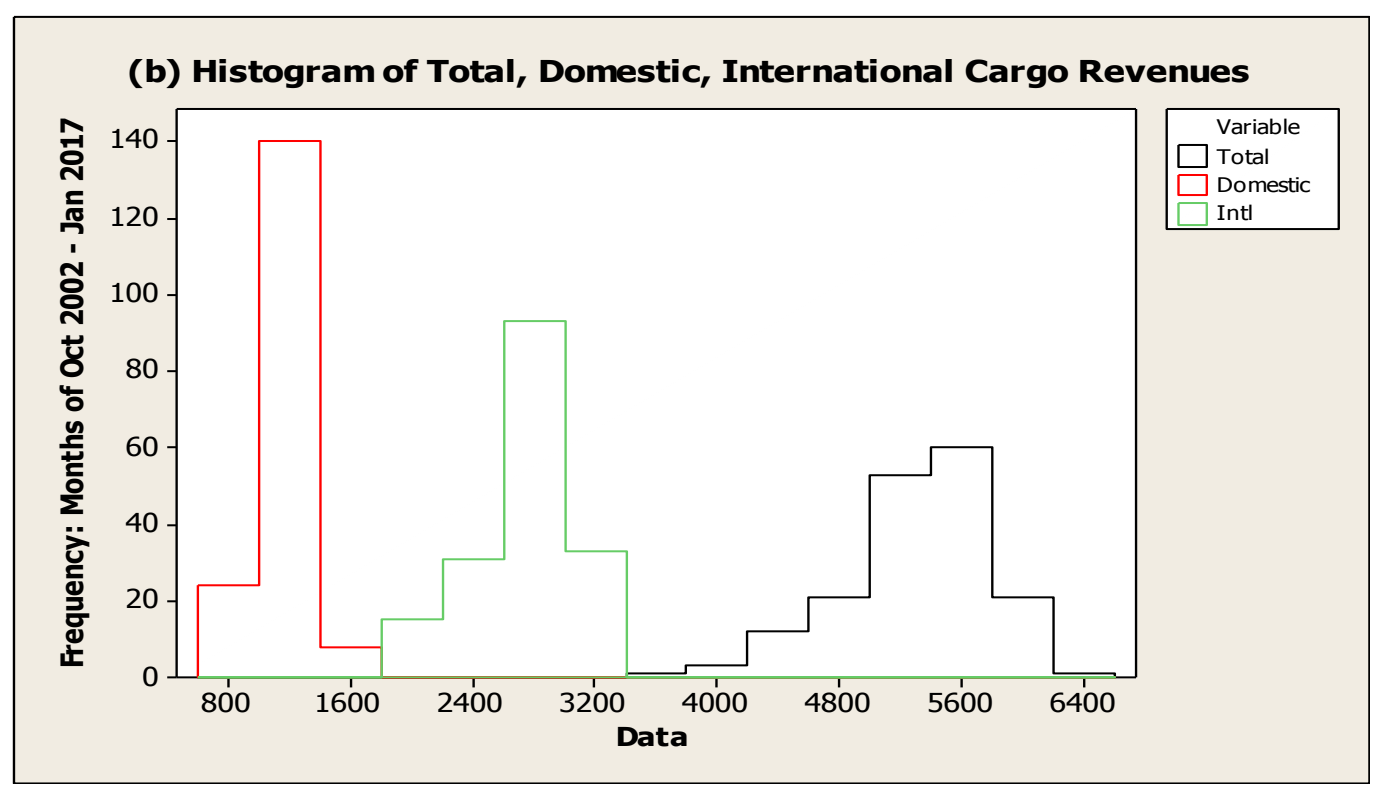

Figure 5

The Three Levels and Frequencies of Air Cargo Revenues

Load factor is a major profitability indicator in aviation. A high load factor is just about a high rate of passenger occupancy conducive to higher profit, given the high fixed costs of fuel, well-maintained aircraft, full flight crew and support staff. Load factor would reflect expected profit index and even a component of the expected risk factor for corresponding investors. As is clear in Figure 6, both trends of load factor and revenues are upward, despite shorter-term fluctuations. 


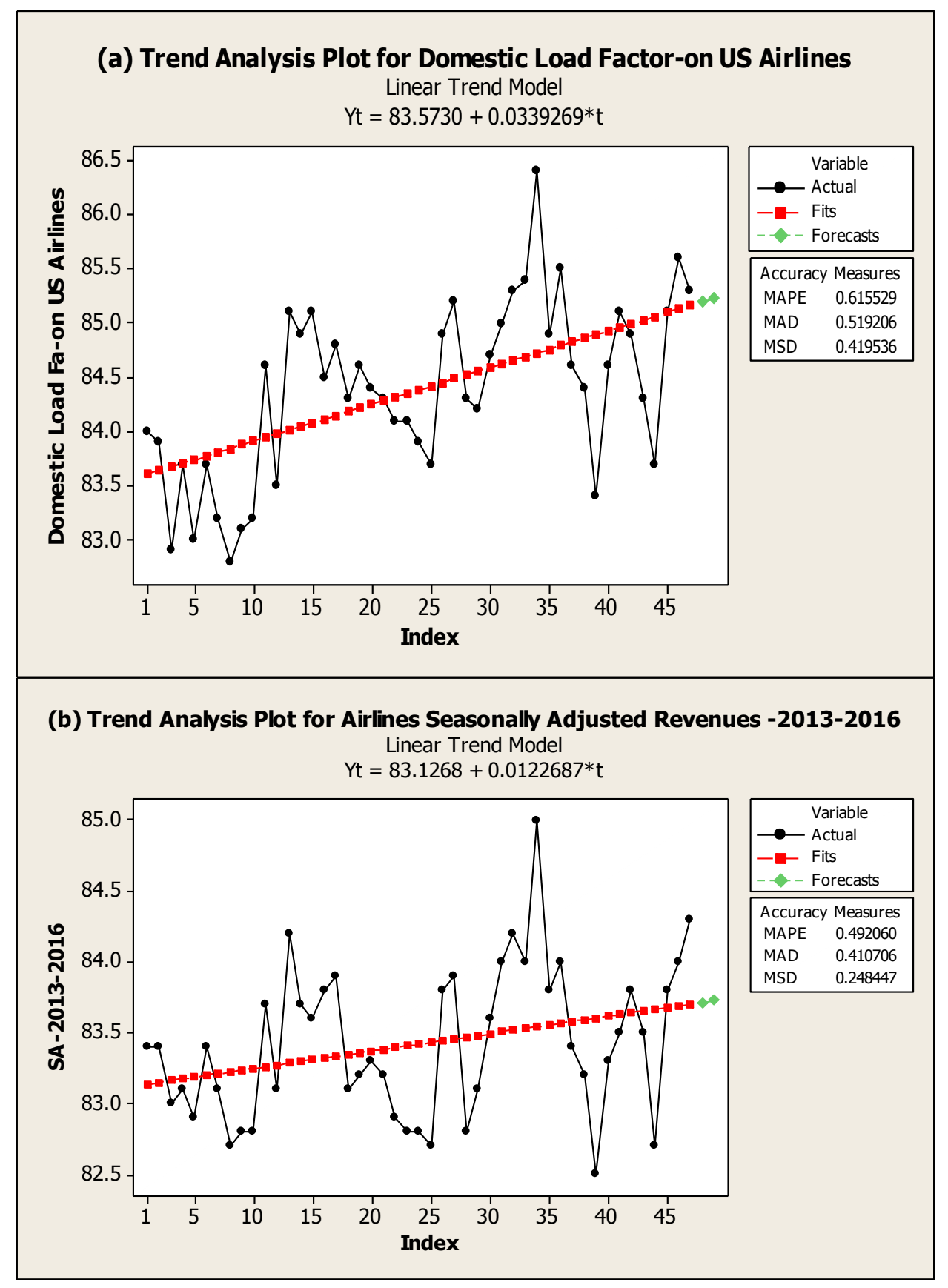

Figure 6

US Airlines' Upward Domestic Load Factor Trend (a) and Revenues Trend (b)

In Figure 7, however the trend behaviors for Air cargo revenues and international load factor are different than those depicted in Figure 6. 


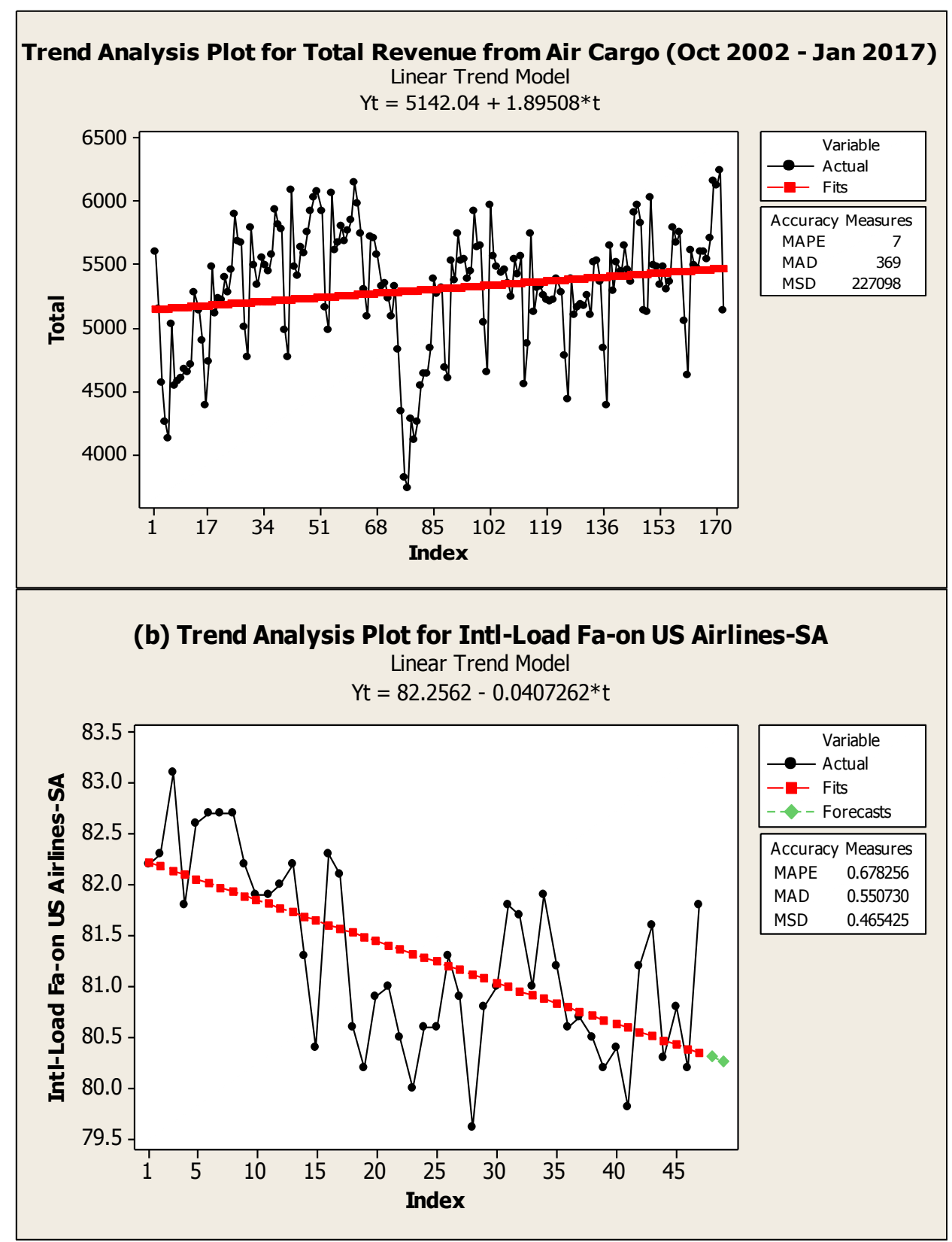

Figure 7

U.S. Cargo Airlines' Total Revenue Trend (a) and Downward International Load Factor Trend (b)

\section{Summary}

The intuitive concept of strong economic effects of aviation and air transport has been unexceptionally supported by the abundantly existing clear evidence. Hence, formulation of a dynamic and sustainable policy is considered as mandatory. Innovative policies would internalize major components of the existing positive externalities to enhance the success, efficiency, and viability of the industry, which would be conducive to undoubted economic 
development for various nations. In this research, the author has formulated three theoretical models that would serve in enhancement of efficiency and efficacy of air transport investment and its subsequent infrastructure impact on the economy. Tax policy that would encourage more environmental improvement, passenger satisfaction, and job creation would play significant roles in the formulated framework. The author is continuing this research in search of more macroeconomic data, involving air transport performance indexation along with matching GDP, and other macroeconomic data.

\section{References}

Air Transport Action Group - ATAG. (July 2016). “A Country-by-Country Look at Aviation's Benefits." Powering Global Economic Growth, Employment, Trade Links, Tourism and Support for Sustainable Development through Air Transport, pp. 61-64.

ATAG. (June 2016). Aviation Benefits beyond Borders - Global Summary.

Button, Ken. (2008). "The Impacts of Globalization on International Air Transport Activity." Global Forum on Transport and Environment in a Globalizing World, held in Guadalajara, Mexico, November 10-12, 2008.

Gill, Michael. (April 2014). Powering Global Economic Growth, Employment, Trade Links, Tourism and Support for Sustainable Development Through Air Transport. Aviation Benefits Beyond Borders. Air Transport Aviation Group (ATAG), Geneva, Switzerland.

Hamzaee, Reza G., and Vasigh, Bijan. (May 2006). "A Collective Airport - Airline Efficiency Strategic Model." The International Journal of Applied Management and Technology. Volume 4, No. 1, pp.67-78.

Hamzaee, Reza G., and Vasigh, Bijan. (May 2002). "Total Factor Productivity Index (TFP) for Airport Efficiency." Handbook of Airline Economics. McGraw Hill Publishing Co., $2^{\text {nd }}$ edition, May 2002, pp. 469-476.

Hamzaee, Reza G., and Vasigh, Bijan. (March 2001). "Airport Efficiency," AVMARK Aviation Economist Journal. March 2001 edition, pp. 10-12.

U.S. Department of Transportation: Federal Aviation Administration. (January 2015). The Economic Impact of Civil Aviation on the U.S. Economy: Economic Impact of Civil Aviation by State.

U.S. Department of Transportation: Data Sources: https://www.rita.dot.gov/bts/sites/rita.dot.gov.bts/files/publications/national transportation_st atistics/html/table $03 \quad 06 . \mathrm{html}$ 


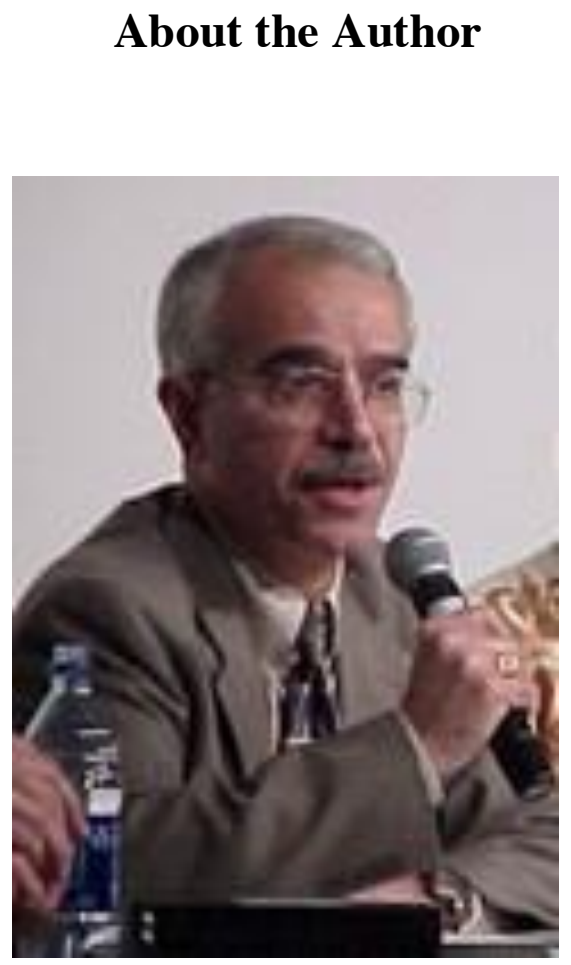

Reza G. Hamzaee: He has been actively serving Missouri Western State University (MWSU) since August 1984. He chaired the Dept. of Business \& Economics @ MWSU in 1990-91. He has earned 8 teaching-excellence and research-excellence awards from MWSU, including two times of post-professorial promotions, under the title of "MWSU Board of Governors Distinguished Professor Award" in 2003 and 2008. He has received several research domestic and international grants. He also served WU's doctoral program at the School of Applied Management \& Decision Sciences for the period of 1992-2014, as his invited second affiliation. 